\title{
Complete Genome Sequence of a Putative Novel Ilarvirus Isolated From Eleocharis Dulcis
}

\section{Lanqing LV \\ Ningbo University \\ Xinyang Wu \\ Ningbo University \\ Jiajia Weng \\ Ningbo University \\ Yuchao Lai \\ Ningbo University \\ Kelei Han \\ Ningbo University \\ Yuwen Lu \\ Ningbo University \\ Jiejun Peng \\ Ningbo University \\ Lin Lin \\ Ningbo University}

Shaofei Rao

Ningbo University

Guanwei Wu

Ningbo University

Jianping Chen

Ningbo University

Hongying Zheng ( $\nabla$ zhenghongyinghz@163.com )

Ningbo University https://orcid.org/0000-0003-0194-3388

\section{Wen Jiang}

Guangxi Academy of Agricultural Science

Fei Yan

Ningbo University

\section{Research Article}


Keywords: Eleocharis dulcis, Complete genome sequence, putative novel ilarvirus, water chestnut virus A (WCVA), next generation sequencing (NGS)

Posted Date: June 15th, 2021

DOI: https://doi.org/10.21203/rs.3.rs-601142/v1

License: (c) (1) This work is licensed under a Creative Commons Attribution 4.0 International License. Read Full License

Version of Record: A version of this preprint was published at Archives of Virology on October 4th, 2021. See the published version at https://doi.org/10.1007/s00705-021-05249-x. 


\section{Abstract}

The complete genomic sequence of a novel ilarvirus from Eleocharis dulcis, tentatively named water chestnut virus A (WCVA), was determined using next generation sequencing (NGS) combined with reverse transcription polymerase chain reaction (RT-PCR) and rapid amplification of cDNA ends (RACE) PCR. The three genomic RNA components of WCVA were 3578 (RNA1), 2873 (RNA2) and 2073 (RNA3) nucleotides long, with four predicted open reading frames containing conserved domains and motifs typical of ilarviruses. Phylogenetic analyses of each predicted protein consistently placed WCVA in subgroup 4 of the genus Ilarvirus, together with prune dwarf virus, viola white distortion associated virus, fragaria chiloensis latent virus and potato yellowing virus. The genetic distances and lack of serological reaction to antisera of other ilarviruses suggest that WCVA is a novel member of the genus.

\section{Background}

Water chestnut (Eleocharis dulcis (Burm. f.) Trin. is a perennial aquatic plant of the genus Eleocharis (Cyperaceae) that occurs naturally in China, Japan, Ryukyu Islands, Nanyang Island and India [1]. Its underground corms can be eaten raw or cooked and are one of the characteristic vegetables in China. There are about 50,000 ha of cultivated water chestnut in China including 20,000 ha in Guangxi province, particularly around Hezhou and Lipu and there is also significant cultivation in Tuanfeng and Shayang counties, Hubei province [2, 3].

Because the plants are propagated vegetatively, viruses are easily transmitted to the next generation when germplasm is exchanged, causing a decline in crop yields and significant economic losses. Several viruses have previously been reported from water chestnuts. Cucumber mosaic virus (CMV) causes chlorosis, dwarfing and deformity and was first identified on water chestnuts in 2014 [4], while a doublestranded DNA virus named water chestnut soymovirus- 1 was discovered by high-throughput sequencing in 2019 [2].

Over the period 2016-2020, it was noticed that the quality of corms of a local water chestnut variety in Guangxi had become degenerated; corms were smaller and the leaves had chlorotic spots. Diseased leaf samples were collected in July 2020 and sent to Zhejiang Academy of Agricultural Sciences (Hangzhou, China) for next generation sequencing (NGS). Total RNAs were extracted with TRIzol (Invitrogen, Carlsbad, USA) and RNA integrity was checked using an Agilent 2100 Bioanalyzer (Agilent Technologies). A cDNA library was constructed with the TruSeq RNA Sample Preparation Kit (Illumina) according to the manufacturer's instructions. An Illumina NovaSeq 6000 platform with PE150bp and CLC Genomic Workbench 11(QIAGEN) was used for sequencing and data analysis with default parameters. A total of $36,026,984$ paired-end reads were obtained, and 12,675 contigs (903 to $18749 \mathrm{bp}$ ) were generated de novo and compared with sequences in GenBank using BLASTn or BLASTx. Three of the contigs (3858nt, $2861 \mathrm{nt}$ and 2144nt) were clearly related to the three genomic RNAs of viruses in the genus Ilarvirus (Bromoviridae) with the highest nucleotide sequence identities of $57.5 \%, 74.0 \%$ and $59.4 \%$ respectively to different members of the genus, suggesting the existence of a distinct ilarvirus. Ilarviruses are a group of 
isometric and labile viruses that are distributed worldwide and infect many hosts including vegetables, ornamentals and fruit trees $[5,6]$. Their genomes encode four or five proteins on three RNA strands, and they have mostly been classified into four phylogenetic sub-groups [7].

To determine the complete genomic RNA sequence of the water chestnut virus, specific primer sets were designed (Supplementary Table 1) to amplify each of the RNAs in two overlapping segments for cloning and splicing. Total RNA was extracted from the infected water chestnut sample using the EASYspin RNA Plant Mini Kit (Aidlab Biotechnologies Co., Ltd, China). Total RNAs were polyadenylated using a Poly(A) Polymerase (TAKARA, Japan), and then reverse transcribed using M4-T primer and the First Strand cDNA Synthesis Kit (Toyobo, Osaka, Japan) [8]. Rapid amplification of cDNA ends (RACE) (Tiosbio, Beijing, China) was used to ensure that the complete sequences were obtained. Each PCR product was inserted into the pEASY-T5 Zero Cloning Vector (TransGen Biotech, Beijing) and more than five clones per reaction were sequenced (ykang, Hangzhou, China). The 5' and 3'RACE fragments amplified by corresponding primers were then assembled using DNAMAN 8.0 software (Lynnon Biosoft, Canada).

The complete genomic sequences of the three RNA segments were 3578nt (RNA1), 2873nt (RNA2) and 2073nt (RNA3) in length (Fig.1) and were deposited in GenBank (accession nos. MZ170696-MZ170698) with the provisional name of water chestnut virus A (WCVA). The 5'untranslated regions (UTRs) of RNA2 and RNA3 of WCVA (49 and $101 \mathrm{nt}$ in length, respectively) both start with TAAA, while the 3'-UTRs of RNA1 and RNA3 both end with GAUGGC. Sequence analysis suggests that WCVA has four ORFs (Fig.1). The single ORF on RNA1 (P1: nt 43-3387; $125.11 \mathrm{kDa}$ ) had two conserved domains predicted by the protein families database (Pfam: http://pfam.xfam.org/ [9]): viral methyltransferase and helicase (Fig.1). In BLASTp the P1 protein of WCVA had the highest amino acid sequence identity (98\% query coverage and $57.3 \%$ identity) to prune dwarf virus (PDV) (ASJ26572). RNA2 also has a single predicted ORF (P2: nt 50-2710; $99.99 \mathrm{kDa}$ ) (Fig. 1) that encodes an RNA-dependent RNA polymerase. The P2 protein had the highest amino acid sequence identity to gungahlin flea-associated ilarvirus (GFAIV) (QIJ70041, 89\% query coverage and $58.1 \%$ identity). RNA3 is predicted to contain two non-overlapping ORFs, encoding a movement protein (MP: nt 102-912; $33.80 \mathrm{kDa}$ ) and a coat protein (CP: nt 1088-1765; 24.76 kDa) (Fig. 1). These had the highest amino acid sequence identities to isolates of potato yellowing virus (PYV) (respectively $85 \%$ query coverage and $61.7 \%$ identity with AZZ70614 and $98 \%$ query coverage and $40.6 \%$ identity with QBO24586).

To determine the relationship between WCVA and other known ilarviruses, phylogenetic trees were prepared for each of the ORFs using representative sequences of all previous reported ilarviruses (Supplementary Table 2) and with CMV (genus Cucumovirus) included as an outgroup. Analysis was conducted in MEGA X [10] using the maximum likelihood method with 1000 bootstrap replicates. In all ORFs, WCVA clustered in subgroup 4 with PDV, viola white distortion associated virus (VWDAV), fragaria chiloensis latent virus (FCILV) and PYV, but the exact clustering pattern among these viruses differed slightly (Fig.2). In addition, the P2 protein of WCVA showed the closest relationship with that of the GFAIV. Howerver, the RNA2 was the only sequence of GFAIV reported so far. Inspection of the trees suggests that three unclassified viruses: surrounding legume associated ilarvirus (SLAIV), grapevine associated 
ilarvirus (GAIV) and solanum nigrum ilarvirus 1 (SNIV-1) are very closely related and are probably members of a single (new) species.

Total protein extracted from leaves of infected water chestnut were tested in DAS-ELISA, with antiserum to the ilarviruses American plum line pattern virus (APLPV), tobacco streak virus (TSV), PDV and prunus necrotic ringspot virus (PNRSV) (Adgia) but there were no positive reactions.

Sequence similarity criteria for demarcation of species within the genus Ilarvirus have not been defined [11] but the low amino acid identities to known ilarviruses in all the predicted proteins $(<62 \%)$ and the serological results all suggest that WCVA is a distinct novel member of the genus. Further research will focus on the incidence of this virus on different water chestnut varieties and its host range and pathogenicity.

\section{Declarations}

\section{Acknowledgements}

We thank Prof. M. J. Adams, Minehead, UK for correcting the English of the manuscript. This work was financially supported by China Agriculture Research System of MOF and MARA (CARS-24-C-04) and sponsored by K. C. Wong Magna Fund in Ningbo University.

\section{Conflict of interest}

The authors declare that they have no conflict of interest.

\section{Ethical approval}

This article does not contain any studies with human participants or animals performed by any of the authors.

\section{Additional information}

The nucleotide sequences reported in this manuscript have been deposited in the GenBank database under accession numbers MZ170696-MZ170698.

\section{References}

1. Li F, Liu Y, Li M, Ke W (2009) Production and research of Chinese water chestnut in the United States. $J$ Changjiang Veg 16:19-22

2. Zhang F, Yang Z, Hong N, Wang G, Wang A, Wang L (2019) Identification and characterization of water chestnut Soymovirus-1 (WCSV-1), a novel Soymovirus in water chestnuts (Eleocharis dulcis). BMC Plant Biol 19(1):159. https://doi.org/10.1186/s12870-019-1761-7 
3. Wu M, Zong Y, Zhao B, Zhu H (2019) Development status, problems and development ideas of a quatic vegetables industry in China. J Changjiang Veg 2:35-41

4. Liu J, Wang Y, Hong N, Wang G, Wang L (2014) The first report of cucumber mosaic virus infecting water chestnut in China. Plant Dis 98(1):164. https://doi.org/10.1094/PDIS-06-13-0663-PDN

5. Tzanetakis IE, Price R, Martin RR (2008) Nucleotide sequence of the tripartite Fragaria chiloensis cryptic virus and presence of the virus in the Americas. Virus Genes 36(1):267-272. https://doi.org/10.1007/s11262-007-0186-9

6. Uyemoto JK (1992) Important diseases of Prunus caused by viruses and other graft-transmissible pathogens in California and South Carolina. Plant Dis 76(1):5

7. Simkovich A, Kohalmi SE, Wang A (2021) Ilarviruses (Bromoviridae). In: Bamford DH, Zuckerman M (eds) Encyclopedia of Virology, 4th edn. Academic Press, Oxford, pp 439-446

8. Chen J, Chen J, Adams MJ (2001) A universal PCR primer to detect members of the Potyviridae and its use to examine the taxonomic status of several members of the family. Arch Virol 146(4):757-766. https://doi.org/10.1007/s007050170144

9. Finn RD, Bateman A, Clements J, Coggill P, Eberhardt RY, Eddy SR, Heger A, Hetherington K, Holm L, Mistry J, Sonnhammer EL, Tate J, Punta M (2014) Pfam: the protein families database. Nucleic Acids Res 42(Database issue):D222-D230. https://doi.org/10.1093/nar/gkt1223

10. Kumar S, Stecher G, Li M, Knyaz C, Tamura K (2018) MEGA X: molecular evolutionary genetics analysis across computing platforms. Mol Biol Evol35(6):1547-1549. https://doi.org/10.1093/molbev/msy096

11. Bujarski J, Gallitelli D, García-Arenal F, Pallás V, Palukaitis P, Krishna Reddy M, Wang A (2019) ICTV virus taxonomy profile: Bromoviridae. J Gen Virol 100:1206-1207.

https://doi.org/10.1099/jgv.0.001282

\section{Figures}


RNA1 (3578 nt)

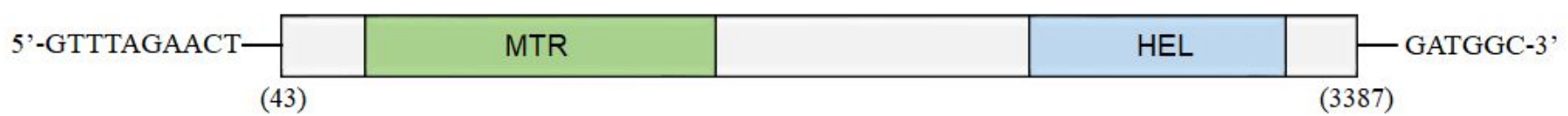

RNA2 (2873 nt)

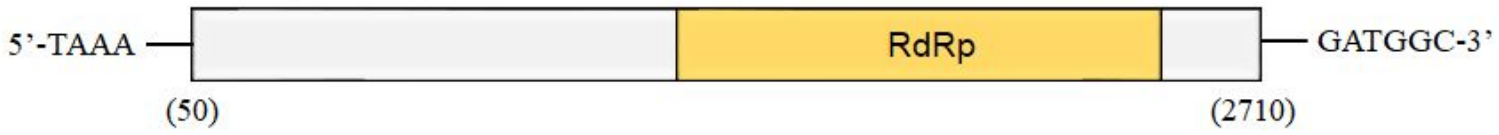

RNA3 (2073 nt)

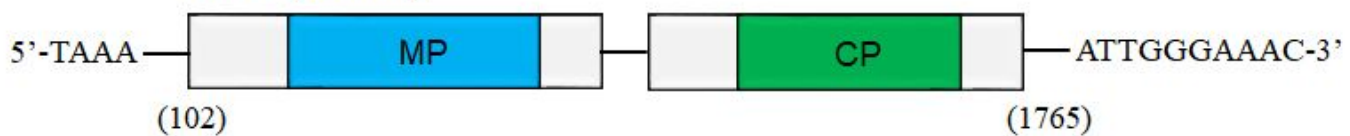

(102)

$(1765)$

: Viral methyltransferase (Pfam: 8.1e-73, S58 - K417)

: Viral (Superfamily 1) RNA helicase (Pfam: 1.1e-55, T816 - T1075)

: RNA dependent RNA polymerase (Pfam: 1.9e-126, N410 - S841)

: Bromovirus movement protein (Pfam: 1.6e-43, T24 - S267)

: Ilarvirus coat protein (Pfam: 7.8e-46, N18 - D217)

\section{Figure 1}

Genome organization of water chestnut virus A (WCVA; GenBank accession nos. MZ170696-MZ170698). Conserved domains/ motifs predicted by Pfam are shown. 


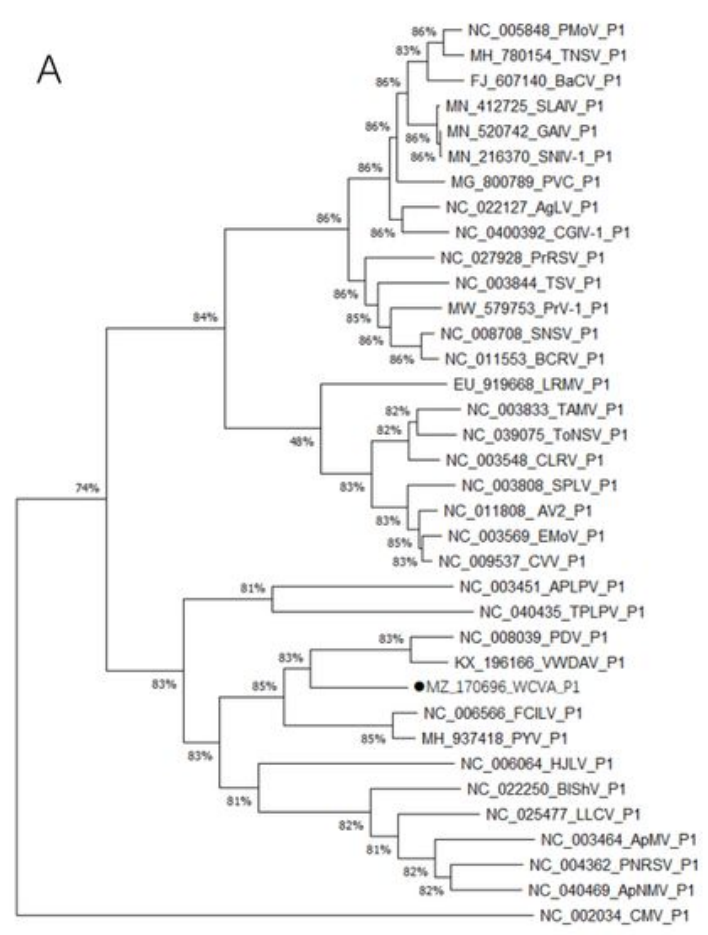

0.20

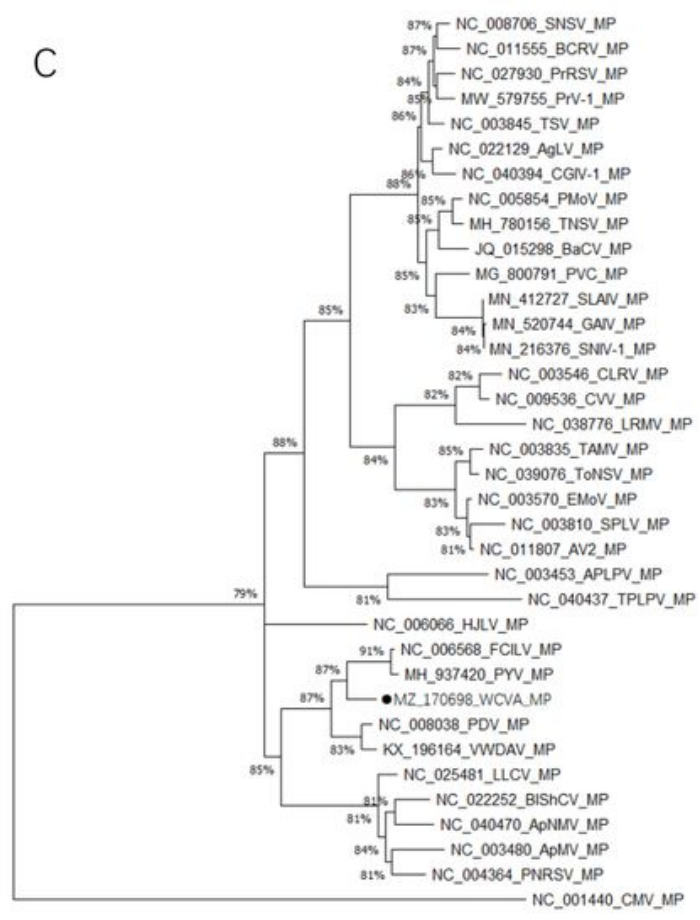

1

Figure 2

Phylogenetic analysis of water chestnut virus A (WCVA; GenBank accession nos. MZ170696-MZ170698) and existing ilarviruses. Phylogenetic trees were constructed based on alignments of complete amino acid sequences of P1 (A), P2 (B), MP (C) or CP (D). Phylogenetic analysis was performed using the maximum-likelihood method in MEGAX. The numbers at each node represent the data coverage. Cucumber mosaic virus (CMV, genus Cucumovirus) was used as an out-group. The acronyms used are as

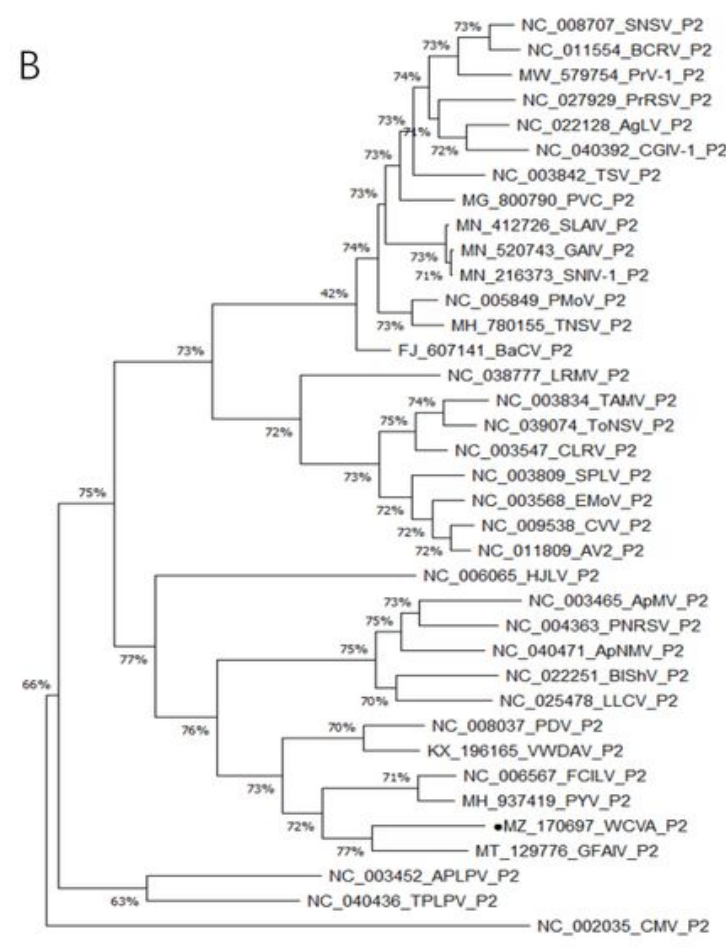

non

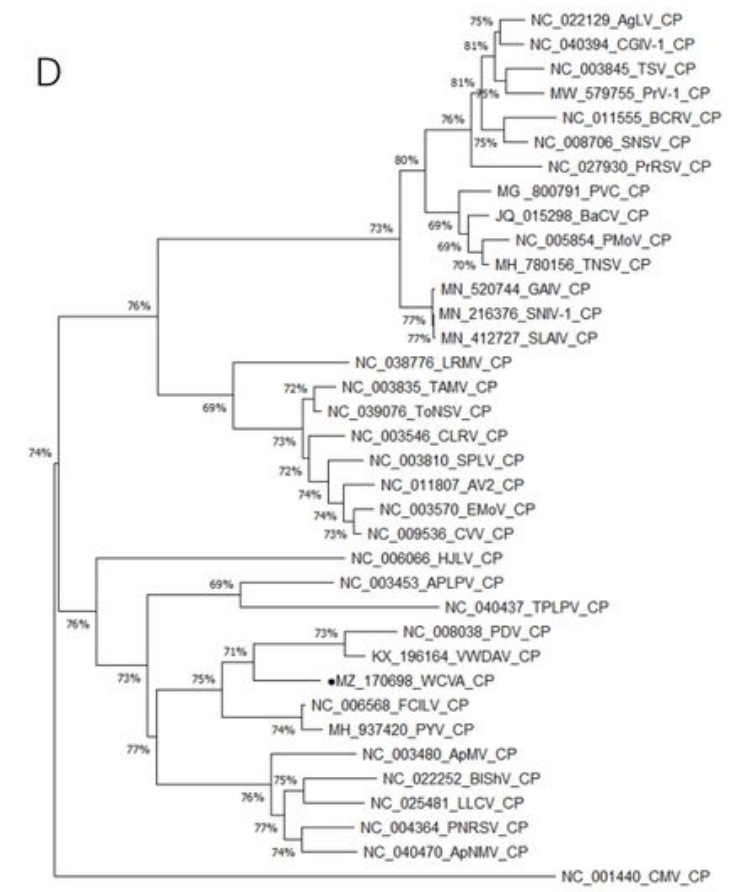

a.so 
follows: Ageratum latent virus, AgLV; American plum line pattern virus, APLPV; Apple mosaic virus, ApMV; Apple necrotic mosaic virus, ApNMV; Asparagus virus 2, AV2; Bacopa chlorosis virus, BaCV; Blackberry chlorotic ringspot virus, BCRV; Blueberry shock virus, BIShV; Cape gooseberry ilarvirus 1, CGIV-1; Citrus leaf rugose virus, CLRV; Citrus variegation virus, CVV; Elm mottle virus, EMoV; Fragaria chiloensis latent virus, FCILV; Grapevine associated ilarvirus, GAIV; Gungahlin flea-associated ilarvirus, GFAIV; Humulus japonicus latent virus, HJLV; Lilac leaf chlorosis virus, LLCV; Lilac ring mottle virus, LRMV; Prune dwarf virus, PDV; Parietaria mottle virus, PMoV; Privet ringspot virus, PrRSV; Prunus necrotic ringspot virus, PNRSV; Prunus virus I, PrV-1; Peanut virus C, PVC; Potato yellowing virus, PYV; Surrounding legume associated ilarvirus, SLAIV; Solanum nigrum ilarvirus 1, SNIV-1; Strawberry necrotic shock virus, SNSV; Spinach latent virus, SPLV; Tobacco streak virus, TSV; Tulare apple mosaic virus, TAMV; Tomato necrotic spot virus, TNSV; Tomato necrotic streak virus, ToNSV; Tea plant line pattern virus, TPLPV; Viola white distortion associated virus, VWDAV.

\section{Supplementary Files}

This is a list of supplementary files associated with this preprint. Click to download.

- Supplementarymaterial.doc

- sequenceinformationofWCVA.fas 